\title{
Toxicity of Modified Magnetite-Based Nanocomposites Used for Wastewater Treatment and Evaluated on Zebrafish (Danio rerio) Model
}

\author{
Amaimen Guillén ${ }^{1,2}$, Yeferzon Ardila ${ }^{2}$, Mabel Juliana Noguera ${ }^{1}{ }^{(}$, , Ana Lucía Campaña ${ }^{1} \mathbb{C}$, Miranda Bejarano ${ }^{2}$, \\ Veronica Akle $^{2}$ and Johann F. Osma ${ }^{1, *(1)}$
}

1 CMUA, Department of Electrical and Electronic Engineering, Universidad de los Andes, Cra. 1E No. 19a-40, Bogotá 111711, Colombia; aa.guillon@uniandes.edu.co (A.G.); mj.noguera10@uniandes.edu.co (M.J.N.); al.campana10@uniandes.edu.co (A.L.C.)

2 Neuroscience and Circadian Rhythms Laboratory, School of Medicine, Universidad de los Andes, Cra 1 No. 18a-10, Bogotá 111711, Colombia; ya.ardila@uniandes.edu.co (Y.A.); sm.bejarano@uniandes.edu.co (M.B.); v.akle@uniandes.edu.co (V.A.)

* Correspondence: jf.osma43@uniandes.edu.co; Tel.: +57-601-339-4949

Citation: Guillén, A.; Ardila, Y.;

Noguera, M.J.; Campaña, A.L.;

Bejarano, M.; Akle, V.; Osma, J.F.

Toxicity of Modified Magnetite-Based

Nanocomposites Used for

Wastewater Treatment and Evaluated

on Zebrafish (Danio rerio) Model.

Nanomaterials 2022, 12, 489. https://

doi.org/10.3390/nano12030489

Academic Editor: Thierry Rabilloud

Received: 6 December 2021

Accepted: 23 January 2022

Published: 29 January 2022

Publisher's Note: MDPI stays neutral with regard to jurisdictional claims in published maps and institutional affiliations.

Copyright: () 2022 by the authors Licensee MDPI, Basel, Switzerland. This article is an open access article distributed under the terms and conditions of the Creative Commons Attribution (CC BY) license (https:// creativecommons.org/licenses/by/ $4.0 /)$.

\begin{abstract}
Magnetite-based nanocomposites are used for biomedical, industrial, and environmental applications. In this study, we evaluated their effects on survival, malformation, reproduction, and behavior in a zebrafish animal model. Nanoparticles were synthesized by chemical coprecipitation and were surface-functionalized with (3-aminopropyl) triethoxysilane (APTES), L-cysteine (Cys), and 3-(triethoxysilyl) propylsuccinic anhydride (CAS). All these nanocomposites were designed for the treatment of wastewater. Zebrafish embryos at $8 \mathrm{~h}$ post-fertilization (hpf) and larvae at 4 days post-fertilization (dpf) were exposed to the magnetic nanocomposites $\mathrm{Fe}_{3} \mathrm{O}_{4} \mathrm{MNP}$ (magnetite), $\mathrm{MNP}+\mathrm{APTES}, \mathrm{MNP}+\mathrm{Cys}, \mathrm{MNP}+\mathrm{APTES}+\mathrm{Cys}$, and MNP+CAS, at concentrations of 1, 10, 100, and $1000 \mu \mathrm{g} / \mathrm{mL}$. Zebrafish were observed until $13 \mathrm{dpf}$, registering daily hatching, survival, and malformations. Behavior was tested at $10 \mathrm{dpf}$ for larvae, and reproduction was analyzed later in adulthood. The results showed that the toxicity of the nanocomposites used were relatively low. Exploratory behavior tests showed no significant changes. Reproduction in adults treated during development was not affected, even at concentrations above the OECD recommendation. Given the slight effects observed so far, these results suggest that nanocomposites at the concentrations evaluated here could be a viable alternative for water remediation because they do not affect the long-term survival and welfare of the animals.
\end{abstract}

Keywords: magnetic nanocomposites; functionalization; zebrafish; survival; malformation; reproduction; ethology

\section{Introduction}

The use of nanocomposites based on different materials has increased widely. Nanocomposites have found applications in different fields such as medical, environmental, cosmetic, electronic, and energy applications, etc. Among these materials, magnetite-based nanoparticles, which have magnetic properties [1,2], are very attractive for various applications [3-7]. The functionalized magnetic nanoparticles are useful in wastewater treatment [8-11] due to their high ratios of surface area to volume and their magnetic properties which allow for easy recovery and reuse. The functionalization of magnetic nanoparticles is achieved by covering the surface of the nanoparticles by physical or chemical means. This method generates a new compound with a magnetic core which can be coated with an organic or inorganic layer, allowing it to have selective properties when used as an absorbent [10,12]. Although initially used for purposes of seeking to mitigate or solve a problem, there are concerns about the potential impact that these materials may have on the environment. 
Therefore, considering the increasing proliferation of the use of different nanomaterials, it is necessary to evaluate the possible effects of magnetite-based nanocomposites on biological systems. Aquatic ecosystems, including freshwater and marine ecosystems, receive the majority of waste or pollutants derived from human activities, such as extraction of resources, waste treatment, and over-exploitation in general [13]. Added to all these activities is the accelerated growth of nanomaterials for various uses, whose potential impact on the environment is unknown.

Lately, zebrafish models have been used to assess the possible impact of various molecules in water. This model organism is the aquatic model recommended by the Organisation for Economic Co-operation and Development (OECD) [14]. Zebrafish have characteristics that allow compliance with the fundamental principle of animal research known as the three Rs (3Rs) (i.e., replacement, reduction, and refinement) [15-17]. Additionally, it is a suitable model because it is a small and robust fish [18] with low maintenance costs [19]. It has rapid organogenesis, and the embryos are almost transparent, making it possible to examine the development of internal structures. Furthermore, about $70 \%$ of zebrafish and human genes are homologous [20] and their physiologies are comparable. For these reasons, zebrafish have been used to study the toxicity and effects of drugs and psychoactive substances on neuronal development and behavior [21]. This is consequently a suitable model for evaluating possible effects produced by magnetite-based nanocomposites.

The magnetite-based nanocomposites evaluated here were designed for the removal of pollutants in wastewater and have been tested on heavy metals such as cadmium [22]. Although the results have been promising, the safety of these nanocomposites in the environment must be guaranteed before their widespread use. Likewise, the toxicity parameters of the magnetite-based nanocomposites presented here have not yet been reported using a zebrafish model.

In this study, we proposed to determine the possible effects on the morphology, survival, behavior, and reproduction of zebrafish subjected to treatments with magnetitebased nanocomposites.

\section{Materials and Methods}

\subsection{Chemicals}

Iron (II) chloride tetrahydrate $(98 \%)\left(\mathrm{FeCl}_{2} * 4 \mathrm{H}_{2} \mathrm{O}\right)$, glutaraldehyde $(25 \%)$, and sodium hydroxide $(\mathrm{NaOH})(98 \%)$ were obtained from PanReac AppliChem (Spain). Iron (III) chloride hexahydrate $(97 \%)\left(\mathrm{FeCl}_{3}{ }^{*} 6 \mathrm{H}_{2} \mathrm{O}\right)$, tetramethylammonium hydroxide (TMAH) $(25 \%)$, (3-aminopropyl) triethoxysilane (APTES) (98\%), and L-cysteine (Cys) (97\%) were purchased from Sigma-Aldrich (USA). In addition, 3-(triethoxysilyl) propylsuccinic anhydride (CAS) $(95 \%)$ was purchased from Shanghai Kayi Chemical Co. (Shanghai, China).

\subsection{Synthesis and Functionalization of Nanoparticles}

Magnetite nanoparticles (MNPs) were synthesized by the chemical coprecipitation method. Iron chloride solution was prepared by stirring $6 \mathrm{~mL}$ of $1 \mathrm{M} \mathrm{FeCl}_{2}$ and $6 \mathrm{~mL}$ of $2 \mathrm{M}$ $\mathrm{FeCl}_{3}$ in Milli-Q water at $1500 \mathrm{rpm}$ agitation and $90{ }^{\circ} \mathrm{C}$. Two solutions of $6 \mathrm{~mL}$ of $2 \%$ v/v of TMAH and $6 \mathrm{~mL}$ of $8 \mathrm{M} \mathrm{NaOH}$ were prepared, then added to the mixture with the aid of a 78-8110C Programmable Touch Screen syringe pump (Cole-Parmer ${ }^{\circledR}$, Vernon Hills, IL, USA) at a $12 \mathrm{~mL} / \mathrm{h}$ flow rate. The resulting MNPs were thoroughly washed and separated using a strong neodymium magnet and Milli-Q water until a $\mathrm{pH}$ of 7.0 was reached. Following this, the MNPs were sonicated for 30 min using a Vibra-Cell VCX 750 (Sonics \& Materials Inc., Newtown, CT, USA).

APTES, Cys, and CAS were used as functionalization molecules; thus, MNPs and four different surface-modified MNPs were studied: MNP+APTES, MNP+Cys, MNP+APTES+Cys, and MNP+CAS. For MNP functionalization, nanoparticle solutions were buffered with $\mathrm{NaOH}$ to reach $\mathrm{pH} 11$ with $50 \mu \mathrm{L}$ of $2 \%(v / v)$ of TMAH, and then sonicated for $20 \mathrm{~min}$. Surface silanization of MNPs with APTES and CAS was carried out by adding $50 \mu \mathrm{L}$ of $2 \%$ $(v / v)$ APTES or pure CAS to the corresponding MNP solution and sonicating for $10 \mathrm{~min}$. 
For Cys functionalization, $50 \mu \mathrm{L}$ of $0.01 \%(w / v)$ Cys was added. The resulting modified MNPs were thoroughly washed using a neodymium magnet with Milli-Q water until a $\mathrm{pH}$ of 7.5 was reached.

A second functionalization layer with Cys on MNP+APTES was produced, to obtain $\mathrm{MNP}+\mathrm{APTES}+\mathrm{Cys}$. This modification was achieved using $50 \mu \mathrm{L}$ of $0.01 \%(w / v)$ Cys sonicated for $10 \mathrm{~min}$, and excess reagent was washed with Milli-Q water. Before zebrafish exposure to MNPs, the nanocomposites were washed thoroughly with zebrafish-recirculationsystem water (electrical conductivity between 600 and $700 \mu \mathrm{s} / \mathrm{cm}$ and pH 7.4-8.0) until pH 7.5 was reached.

\subsection{Nanocomposites Characterization}

The MNPs size was studied by dynamic light scattering (DLS) using a Zetasizer Nano ZS, (Malvern Panalytical, Malvern, Worcestershire, UK). The sample was prepared by taking the synthesized MNPs and diluting to 3\% $(w / v)$ in $1 \mathrm{~mL}$ of Milli-Q water with $100 \mu \mathrm{L}$ TMAH. The surface modification of MNPs with APTES, CAS, and Cys was analyzed via Fourier-transform infrared spectroscopy (FTIR) using a Bruker ALPHA II FTIR Eco-ATR (Bruker, Germany). Spectra were collected in the range of $4000-500 \mathrm{~cm}^{-1}$.

\subsection{Fish Husbandry, Embryo Collection, and Exposure}

Wild-type TABS zebrafish were raised in the facilities of the Laboratory of Neuroscience and Circadian Rhythms, School of Medicine, Universidad de los Andes, Bogotá, Colombia. All procedures with animals were approved by the Institutional Animal Care and Use Committee of Universidad de los Andes (CICUAL in Spanish) with the code C.FUA_19-004. The animals were bred in an automatic recirculation system (Aquaneering Inc., San Diego, CA, USA) with optimal water conditions for the species $\left(28 \pm 0.5^{\circ} \mathrm{C}\right.$, electrical conductivity between 600 and $700 \mu \mathrm{S} / \mathrm{cm}, \mathrm{pH} 7.4-7.6$, and a 14:10 h light-dark photoperiod). Animals were fed twice a day with Aquatox Fish Diet rearing food from Zeigler, enriched with live brine shrimp (A. salina-INVE Aquaculture, Inc., Salt Lake City, UT, USA). The development of the zebrafish embryo and larvae were observed using an AZ1000M stereoscopic microscope (Nikon, Tokyo, Japan). Zebrafish used for exposure were obtained from spawning adults in crossing tanks.

\subsection{Treatments}

Five types of magnetic nanocomposites were evaluated following the OECD guide for embryonic toxicity tests with additional analysis [14]. Briefly, all nanocomposites were evaluated at concentrations of 1, 10,100, and $1000 \mu \mathrm{g} / \mathrm{mL}$. Animals at $8 \mathrm{hpf}$ and $4 \mathrm{dpf}$ were exposed to the nanocomposites for $96 \mathrm{~h}$ with treatment changes every $24 \mathrm{~h}$, maintaining the temperature, $\mathrm{pH}$, and conductivity conditions. Groups of 30 animals per concentration were used, divided into three wells in a six-well plate. Egg water was used as a control, and observations were made every day. The experimental time is described in the Supplementary Material, Figure S1.

\subsection{Mortality, Hatching, and Malformations}

During nanocomposite treatment days, observations were made to determine toxicity on embryos and larvae. The mortality of embryos and larvae fish was determined by daily observations of movement, heartbeat, and blood circulation [23] using a stereoscopic microscope (AZ1000M, Nikon, Japan). Embryos were treated at $8 \mathrm{hpf}$, and their morphological abnormalities were recorded at 24, 48, 72, and $96 \mathrm{~h}$ using the stereoscopic microscope, classified according to the OECD protocols into groups such as coagulated embryos, lack of somite formation, non-detachment of the tail, and lack of heartbeat [14]. Hatching was observed between 48 and $120 \mathrm{hpf}$. A similar procedure was used on the larvae treated at an age of $4 \mathrm{dpf}$ and exposed for $96 \mathrm{~h}$. During the treatment period, the animals were not fed or allowed to have contact with other individuals in the laboratory. Both groups were fed from the ninth day to the end of the observations and euthanized according to 
the laboratory protocols. Malformations and survival data were taken up to $13 \mathrm{dpf}$. The malformations were classified as edemas or abnormalities [23,24].

\subsection{Reproduction Test}

Fish exposed to the nanocomposites at $1000 \mu \mathrm{g} / \mathrm{mL}$ for $96 \mathrm{~h}$ between $8 \mathrm{hpf}$ and $96 \mathrm{hpf}$ that survived, were later used for evaluation of the effect on their reproduction. They were raised in an independent system for up to 1 year and crossed between themselves. The fertilized embryos were monitored for survival for 13 days. Reproduction crosses were made between treated males and treated females. In addition, crosses of treated females with untreated males, and crosses within groups of untreated animals were performed as reference controls.

\subsection{Behavioral Tests}

Groups of 30 zebrafish larvae at $6 \mathrm{dpf}$ were exposed to each of the five types of magnetic nanocomposites at concentrations of 10 and $100 \mu \mathrm{g} / \mathrm{mL}$ for $96 \mathrm{~h}$. At $10 \mathrm{dpf}$, animals underwent behavioral testing, including open-field, startle response, and color preference tests, using a DanioVision Observation Chamber and the results were analyzed with EthoVision ${ }^{\circledR}$ XT 14 software (Noldus Information Technology, Wageningen, The Netherlands). Open-field videos were recorded for $5 \mathrm{~min}$, and then the distance traveled, average speed, and freezing time of the animals were analyzed. After that, the startle response time was evaluated (the animal's reaction time to a single white light flash of $0.1 \mathrm{~s})$. The distance traveled, speed, and elongation during the $5 \mathrm{~s}$ before and after the flash of light were measured. Another group of treated animals were studied for the color preference test. For this test, the wells of a 6-well plate were divided into two regions, one green and the other transparent, while the behavior of the larvae in terms of time and frequency of entry into each region was monitored.

\subsection{Statistical Analysis}

Survival, hatching, and malformations were evaluated using two-way ANOVA (with nanocomposite type and concentration as factors), followed by a post hoc Bonferroni test, and were expressed as the mean \pm standard error of the mean (SEM). Reproduction data on animals treated with nanocomposites were analyzed using one-way ANOVA followed by a post hoc Tukey test, and were expressed as the mean \pm SEM. Behavior data for treated larvae from 6 to $10 \mathrm{dpf}$ were analyzed with one-way ANOVA followed by a post hoc Tukey test, and were expressed as the mean \pm SEM. The statistical analyses were developed in Minitab 19 Statistical Software, and the level of significance was defined as $p \leq 0.05$ for all comparisons.

\section{Results}

\subsection{MNPs Characterization}

MNPs showed a size distribution with a mean particle size of $125.70 \pm 68.05 \mathrm{~nm}$. The polydispersity index (PDI) of 0.233 indicated that the synthesized particles exhibited uniform sizes (Figure 1a). Figure $1 \mathrm{~b}$ shows the IR spectra of the MNPs before and after the surface modification. Peaks near 1100 and $800 \mathrm{~cm}^{-1}$ were attributed to Si-O-Si and Si-O stretching vibrations, respectively [25]. These bands were found in the modified MNPs as shown, and they provided further evidence of the correct silanization of the surface. Peaks around $1800 \mathrm{~cm}^{-1}$ due to $\mathrm{C}=\mathrm{O}$ stretching of the anhydride group in CAS can also be seen on MNPs modified with CAS. Peaks around $3500-3000 \mathrm{~cm}^{-1}$ and $1620 \mathrm{~cm}^{-1}$ can be related to O-H stretching of carboxyl group and C-C stretching, respectively, and could be found in glutaraldehyde and Cys in the MNPs modified with CAS and APTES+Cys. N-H stretching present in APTES and Cys was observed as a broad absorption band around $3200-3600 \mathrm{~cm}^{-1}$, which can be attributed to free amine groups after conjugation of these molecules with MNPs. MNPs exhibited adsorption bands around $700-600 \mathrm{~cm}^{-1}$, which can be attributed to the Fe-O bond of iron oxide [26]. Weak bands at $2700-3000 \mathrm{~cm}^{-1}$ 
in modified MNP spectra were related to the $\mathrm{C}-\mathrm{H}$ stretching vibration that is also found in pure APTES, CAS, and Cys. However, the zeta potential of the nanocomposites was expected to be negative for MNP, MNP+Cys, and MNP+CAS in the ranges of -31.9 to $-45.9 \mathrm{mV}[27,28],-30$ to $-60 \mathrm{mV}[29,30]$, and $-40 \mathrm{mV}$ [31], respectively. For the APTESfunctionalized nanocomposites, positive zeta potentials were expected in the range from 29.1 to $47.5 \mathrm{mV}[32,33]$ evaluated at neutral $\mathrm{pH}$ values (7.0 to 7.5).

(a)

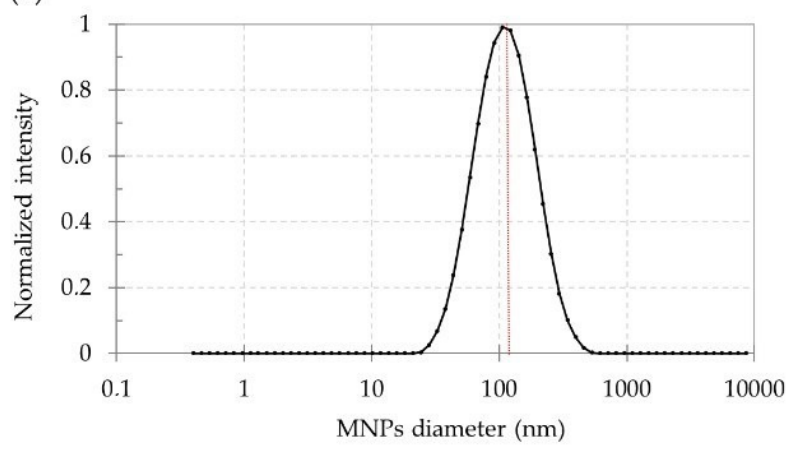

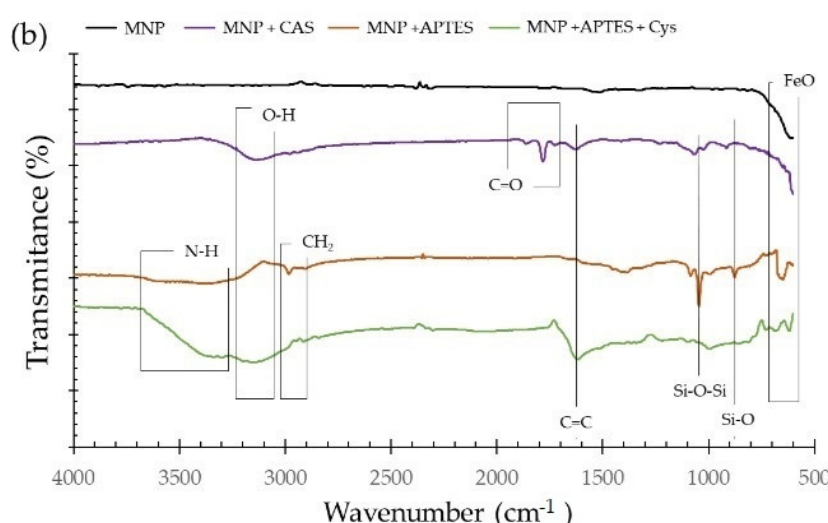

Figure 1. (a) DLS result of size distribution of MNPs solution with mean size centered at $125.70 \pm 68.05 \mathrm{~nm}$. (b) FTIR spectra of MNPs and modified MNPs with CAS, APTES, and APTES+Cys.

\subsection{Exposure to Nanocomposites in Embryos}

Exposure to magnetic nanocomposites did not alter the embryo hatching rates compared to the control group, and hatching occurred in all groups until the fifth dpf. However, a low hatching rate was observed for the MNP+CAS-treated group at $100 \mu \mathrm{g} / \mathrm{mL}$, up to $26 \%$ less than in the control, as shown in Figure $2 \mathrm{a}$, and $16 \%$ less than for the concentrations of 1 and $10 \mu \mathrm{g} / \mathrm{mL}$ in the same nanocomposite group. Embryos from all groups started to hatch after $72 \mathrm{hpf}$, although there were at least two hatchings in groups other than the control at $2 \mathrm{dpf}$ (MNP, MNP+APTES+Cys, and MNP+CAS at $100 \mu \mathrm{g} / \mathrm{mL}$, as shown in Figure 2a) and in the MNP+APTES group at $10 \mu \mathrm{g} / \mathrm{mL}$ (Figure 2b). Overall, hatching was dependent on the concentration of the nanocomposites, and averaged 85,81 , and $79 \%$ for concentrations of 1, 10, and $100 \mu \mathrm{g} / \mathrm{mL}$, respectively. Embryos that did not hatch during treatment were classified as coagulated embryos, lack of somite formation, non-detachment of the tail, or lack of heartbeat [23].

Survival was evaluated up to $13 \mathrm{dpf}$, as shown in Figure 3. It can be seen that the control group had the highest survival rates, between 10 and $16 \%$ more than the average of the groups treated with nanocomposites, and it is also shown that as the concentration of nanocomposites increased, survival decreased. Survival in the treatment groups was significantly different compared to the control $\left(p=2 \times 10^{-10}\right)$. Embryos treated with $\mathrm{MNP}+\mathrm{APTES}$ presented, at the end of the observations, the same survival percentage (73\%) at the three concentrations evaluated $(1,10$, and $100 \mu \mathrm{g} / \mathrm{mL})$, as shown Figure $3 \mathrm{~b}$. Embryos treated with MNP+APTES+Cys and MNP+CAS showed average survival rates of 71 and $66 \%$, respectively; the lowest of all groups, as shown in Figure 3c, e. After the control group, the embryos treated with $\mathrm{MNP}+\mathrm{Cys}$ had the highest survival rates, with an average of $81 \%$; $5.5 \%$ less than the control group, as shown in Figure $3 \mathrm{~d}$. 
(a)

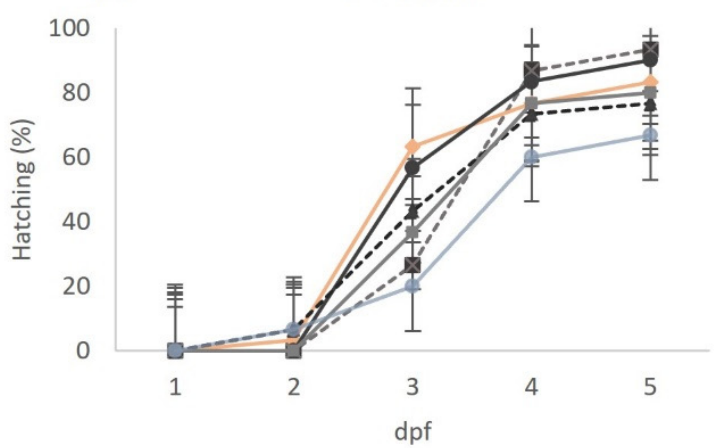

-- Control $\longrightarrow$ MNP $\longrightarrow$ MNP+APTES

-- --MNP+APTES+Cys $\longrightarrow$ MNP+Cys $\longrightarrow$ MNP+CAS

(b)

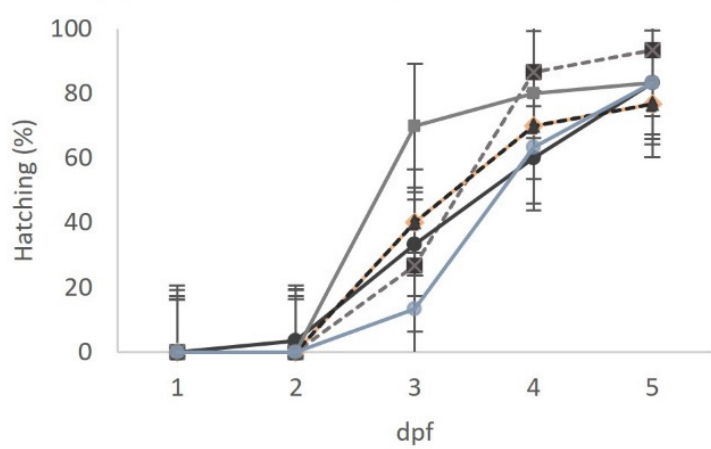

(c)

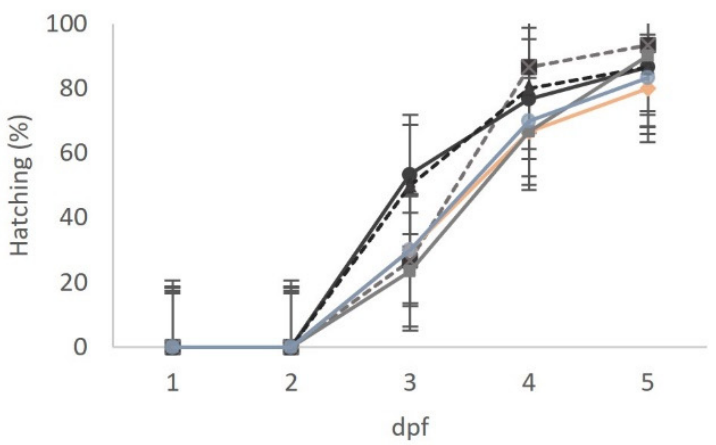

Figure 2. Percentage hatching in embryos treated with nanocomposites compared with the control group. (a) Treatments at concentration of $100 \mu \mathrm{g} / \mathrm{mL}$. (b) Treatments at concentration of $10 \mu \mathrm{g} / \mathrm{mL}$. (c) Treatments at concentration of $1 \mu \mathrm{g} / \mathrm{mL}$. Data are shown as percentage of hatchings \pm SEM ( $n=180$ embryos per concentration).

(a) MNP

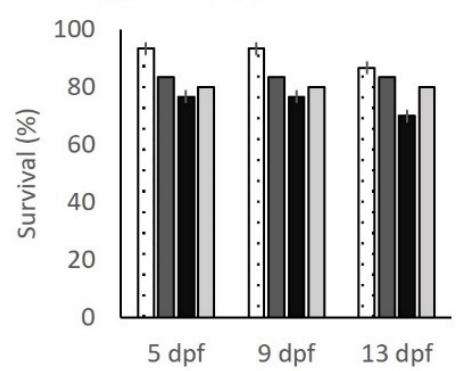

(c) MNP+APTES+Cys

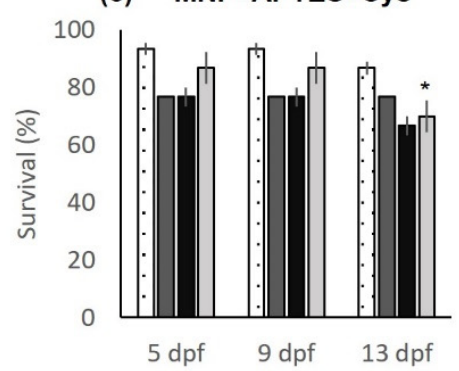

(b)

MNP+APTES

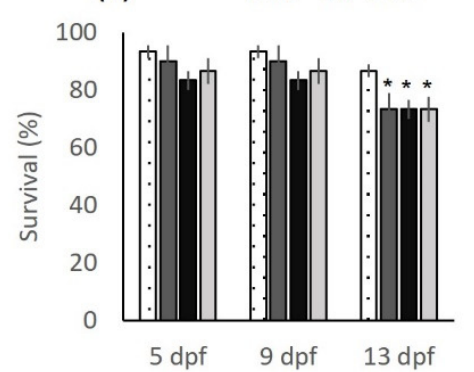

(d) MNP+Cys

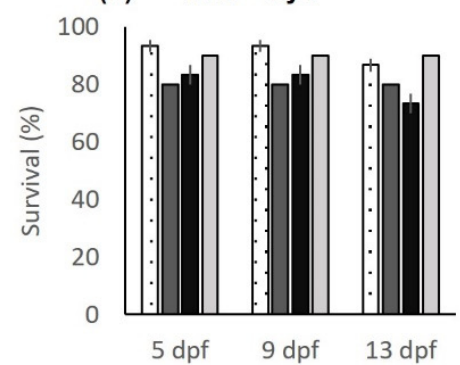

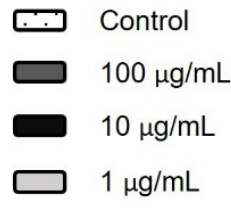

(e) MNP+CAS

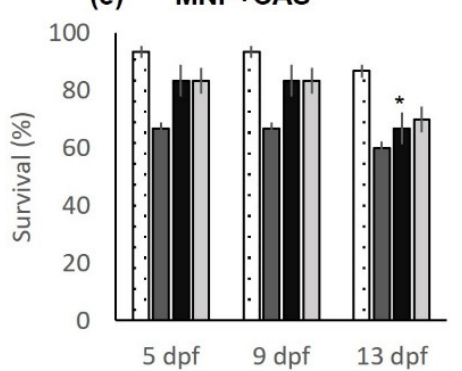

Figure 3. Survival analysis of embryos treated with nanocomposites: (a) magnetite nanoparticles (MNPs); (b) MNP+APTES; (c) MNP+APTES+Cys; (d) MNP+Cys; (e) MNP+CAS. Data are expressed as the mean $\pm \operatorname{SEM}(n=30)$. The ${ }^{*}$ represents significant difference $p \leq 0.05$ in relation to control group. 


\subsection{Exposure to Nanocomposites in Larvae}

Statistically different survival rates were observed for animals treated with MNP+ APTES+Cys, as shown in Figure $4 \mathrm{c}$ with $p=0.004$. These larvae presented the lowest survival rates up to $13 \mathrm{dpf}$ for each of the concentrations evaluated, at 77, 63, and 43\% for concentrations of 1,10 , and $100 \mu \mathrm{g} / \mathrm{mL}$, respectively. Only survival at $13 \mathrm{dpf}$ was dependent on concentration for this treatment. All exposed larvae survived each treatment from $5 \mathrm{dpf}$ to $8 \mathrm{dpf}$ but started to die after $10 \mathrm{dpf}$ (Figure 4 ). However, at the end of the observation period ( $13 \mathrm{dpf})$, the average survival rate of all the animals treated with nanocomposites was higher than $82 \%$. Only the larvae treated with MNP+APTES+Cys presented an average survival percentage below this value $(61 \%)$.

(a)

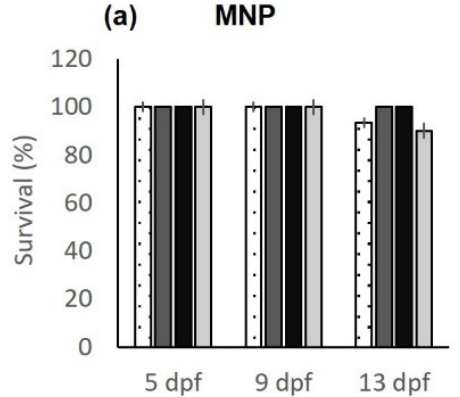

(c) MNP+APTES+Cys

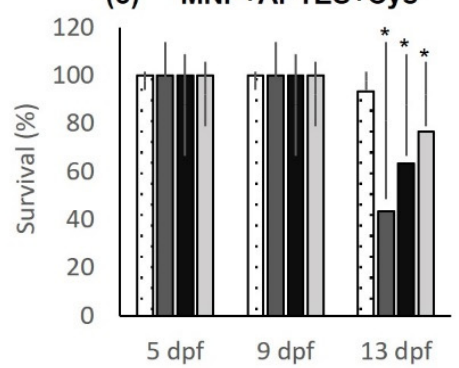

(b)

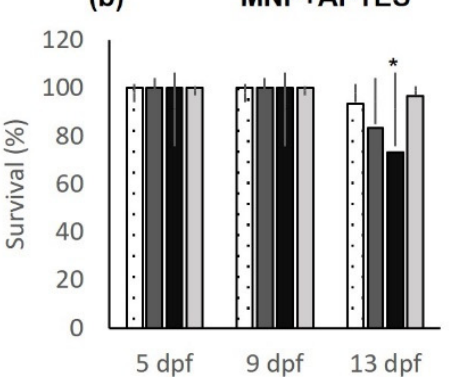

(d) MNP+Cys

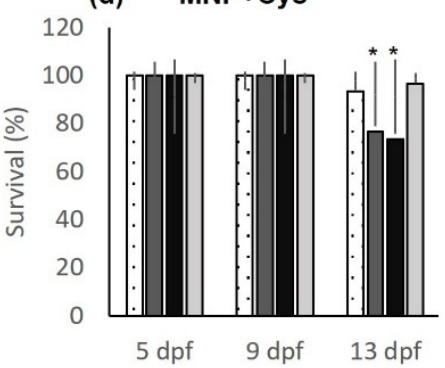

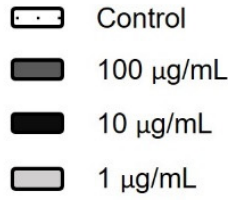

(e) MNP+CAS

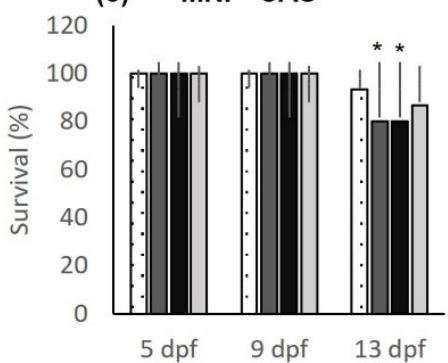

Figure 4. Survival analysis for larvae treated with nanocomposites: (a) magnetite nanoparticles (MNPs); (b) MNP+APTES; (c) MNP+APTES+Cys; (d) MNP+Cys; (e) MNP+CAS. Data are expressed as the mean $\pm \operatorname{SEM}(n=30)$. The ${ }^{*}$ represents significant difference $p \leq 0.05$ in relation to control group.

Malformations appeared at $48 \mathrm{~h}$ after the beginning of the treatments $(6 \mathrm{dpf})$ for the $\mathrm{MNP}+\mathrm{CAS}$ group at $100 \mu \mathrm{g} / \mathrm{mL}$ and the MNP+APTES+Cys and MNP+Cys groups at $1 \mu \mathrm{g} / \mathrm{mL}$. Slight kyphosis was evident on some animals (Figure 5b,c). The group of animals treated with MNP+APTES+Cys was the only one that presented a statistically significant high number of malformations at the three concentrations evaluated $\left(p=1.97 \times 10^{-10}\right)$, with $27 \%$ at $1 \mu \mathrm{g} / \mathrm{mL}$ and $33 \%$ at 10 and at $100 \mu \mathrm{g} / \mathrm{mL}$.

\subsection{Behavior Test}

Exposure to magnetic nanocomposites appears to slightly alter the behavior of zebrafish larvae. The shortest distances traveled were observed in MNP-treated animals independently of the concentration. In fact, animals treated with MNP at concentrations of 10 and $100 \mu \mathrm{g} / \mathrm{mL}$ presented $35.6 \%$ and $59.7 \%$ lower distances traveled compared to the control groups, as shown in Figure $6 \mathrm{a}$ and Table 1 . However, comparisons between treatment and control groups were not shown to be statistically significant $(p=0.113)$. There was a statistically significant difference only at the concentration of $100 \mu \mathrm{g} / \mathrm{mL}$, with $p=0.0192$, for animals treated with MNP+APTES+Cys. This group presented a $63.8 \%$ greater distance traveled than the control group. For average speed, the behavior was similar, as shown in Figure $6 \mathrm{~b}$ and Table 2. A statistically significant difference was presented for the animals treated with MNP+APTES+Cys, with $p=0.0196$. Freezing time, which is a measure of fear, showed that the animals treated with MNP and MNP+APTES, regardless 
of the concentration used, presented the highest averages for this measure compared to the control groups, with $6.27 \%$ and $4.92 \%$ increases, respectively, as shown in Figure 6c. However, when compared by concentration, the difference was not statistically significant at $10 \mu \mathrm{g} / \mathrm{mL}$ but at $100 \mu \mathrm{g} / \mathrm{mL}$, the animals treated with MNP+APTES+Cys showed a statistically significant difference, with $p=4.6 \times 10^{-5}$.

(a)

(b)

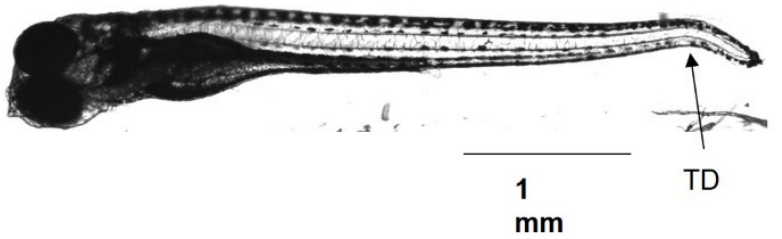

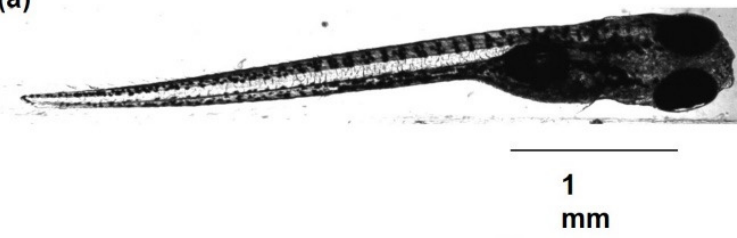

(c)

Figure 5. Microscopic representative images of normal and malformed larvae after hatching, which were exposed to different magnetite nanocomposites (magnification: $5 \times$ ). (a) Normally developed larva (7 dpf). (b) Larva (10 dpf) treated to $4 \mathrm{dpf}$ with MNPs at $100 \mu \mathrm{g} / \mathrm{mL}$. (c) Larva (10 dpf) treated to $4 \mathrm{dpf}$ with $\mathrm{MNP}+\mathrm{CAS}$ at $100 \mu \mathrm{g} / \mathrm{mL}$. Abbreviations: SK: slight kyphosis; TD: tail deformation.

Table 1. Distance traveled $(\mathrm{cm})$ during the open-field test in larvae that were subjected to nanocomposite treatments at 10 and $100 \mu \mathrm{g} / \mathrm{mL}$ between 6 and $10 \mathrm{dpf}$.

\begin{tabular}{ccccc}
\hline \multirow{2}{*}{ Nanocomposite } & \multicolumn{4}{c}{ Distance Traveled $\mathbf{( c m )}$} \\
\cline { 2 - 5 } & $\mathbf{1 0 0} \boldsymbol{\mu \mathbf { g } / \mathbf { m L }}$ & $\mathbf{S E M}$ & $\mathbf{1 0} \boldsymbol{\mu g} / \mathbf{m L}$ & $\mathbf{S E M}$ \\
\hline MNP & 21.92 & 8.38 & 27.90 & 5.10 \\
MNP+APTES & 40.20 & 22.85 & 42.15 & 10.14 \\
MNP+APTES+Cys & 91.45 & 11.64 & 31.62 & 7.27 \\
MNP+Cys & 72.17 & 18.95 & 39.65 & 26.98 \\
MNP+CAS & 29.73 & 14.18 & 47.87 & 10.88 \\
Control & 55.83 & 10.03 & 43.30 & 4.34 \\
\hline
\end{tabular}

Table 2. Velocity $(\mathrm{cm} / \mathrm{s})$ during the open-field test in larvae that were subjected to nanocomposite treatments at 10 and $100 \mu \mathrm{g} / \mathrm{mL}$ between 6 and $10 \mathrm{dpf}$.

\begin{tabular}{ccccc}
\hline \multirow{2}{*}{ Nanocomposite } & \multicolumn{4}{c}{ Velocity $(\mathbf{c m} / \mathbf{s})$} \\
\cline { 2 - 5 } & $\mathbf{1 0 0} \boldsymbol{\mu \mathbf { g } / \mathbf { m L }}$ & $\mathbf{S E M}$ & $\mathbf{1 0} \boldsymbol{\mu g} / \mathbf{m L}$ & SEM \\
\hline MNP & 0.07 & 0.02 & 0.09 & 0.01 \\
MNP+APTES & 0.13 & 0.07 & 0.14 & 0.03 \\
MNP+APTES+Cys & 0.30 & 0.04 & 0.10 & 0.02 \\
MNP+Cys & 0.24 & 0.06 & 0.13 & 0.09 \\
MNP+CAS & 0.09 & 0.04 & 0.15 & 0.03 \\
Control & 0.18 & 0.03 & 0.14 & 0.01 \\
\hline
\end{tabular}


(a)

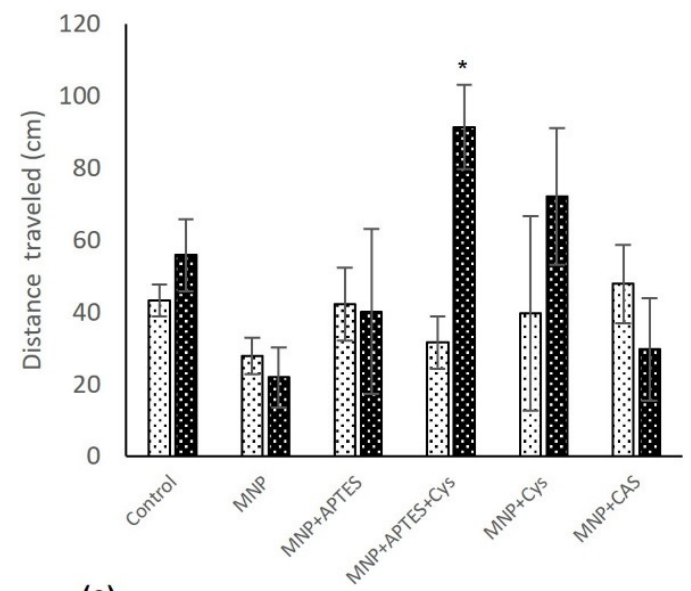

(b)

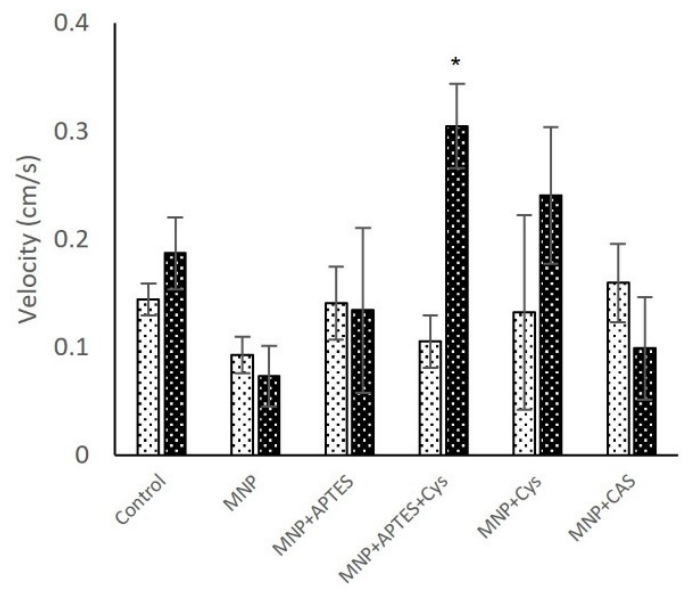

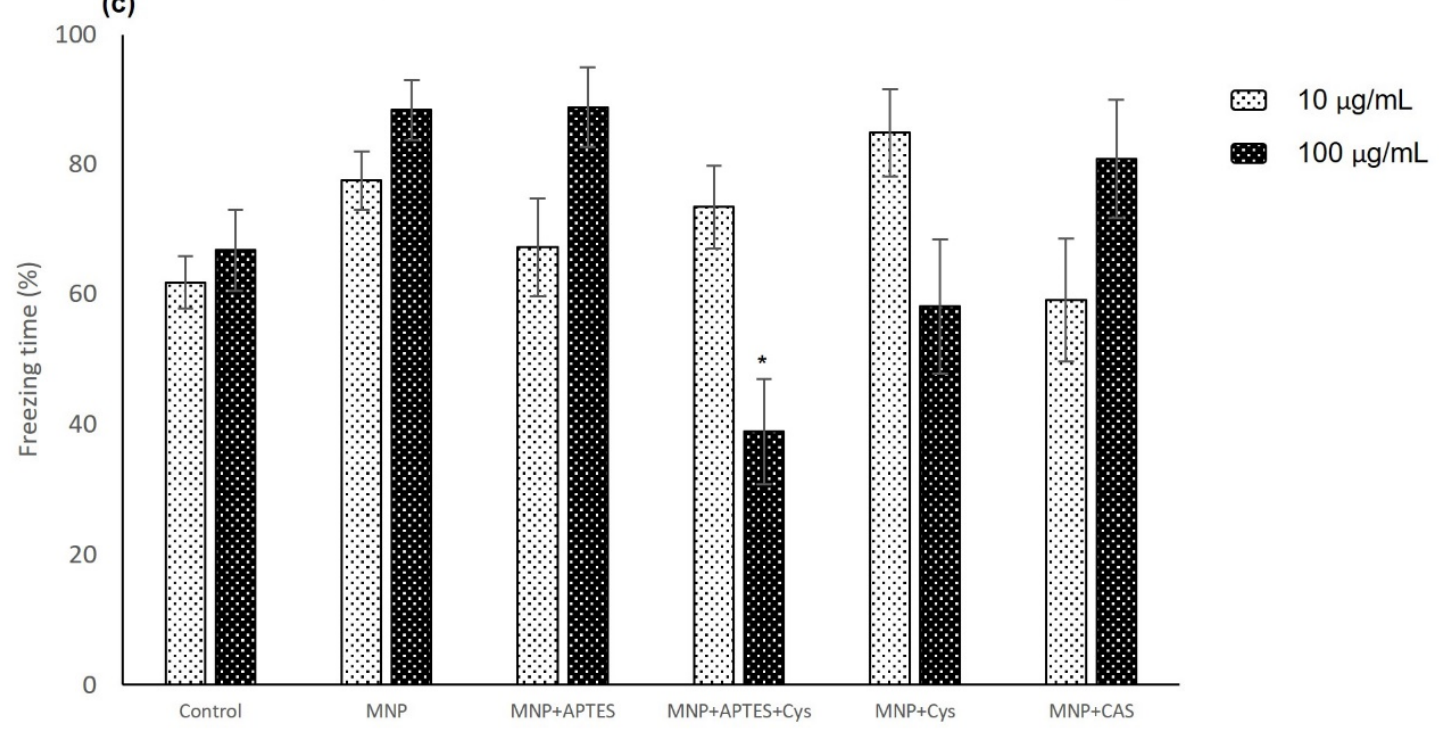

Figure 6. Open-field analysis in larvae that were subjected to nanocomposite treatments at 10 and $100 \mu \mathrm{g} / \mathrm{mL}$ between 6 to $10 \mathrm{dpf}$ : (a) distance traveled; (b) average speed; (c) freezing time. Data are expressed as the mean $\pm \operatorname{SEM}(n=15)$. The ${ }^{*}$ represents significant difference $p \leq 0.05$ in relation to control group.

The startle response test evaluated the animal's reaction time to a single $0.1 \mathrm{~s}$ flash of white light, measuring distance traveled, average speed, and body elongation. The analysis was based on the measurement of these variables during the $5 \mathrm{~s}$ before and after the light flash. In general, animals treated with nanocomposites showed a decreased distance traveled and speed after the light flash, except those treated with MNP+CAS at the concentration of $10 \mu \mathrm{g} / \mathrm{mL}$, as shown in Figure $7 \mathrm{a}, \mathrm{b}$ and Tables 3 and 4 . When compared by concentration, the larvae treated at $10 \mu \mathrm{g} / \mathrm{mL}$ and $\mathrm{MNP}+\mathrm{Cys}$ showed the highest distance traveled and speed values in relation to the control group, by up to $17.4 \%$. In contrast, larvae treated with MNP+APTES+Cys showed values below those of the control group for the distance traveled and speed variables during the test, by $55.5 \%$. For the concentration of $100 \mu \mathrm{g} / \mathrm{mL}$, the larvae treated with MNP+APTES+Cys and MNP+Cys presented values of distance traveled and speed above those of the control group after the light flash, by $21.1 \%$ and $2.5 \%$, respectively. However, the results showed that the differences between the groups were not statistically significant. Finally, body elongation at concentration of 10 and $100 \mu \mathrm{g} / \mathrm{mL}$ were not statistically different (Figure 7c). 
(a)

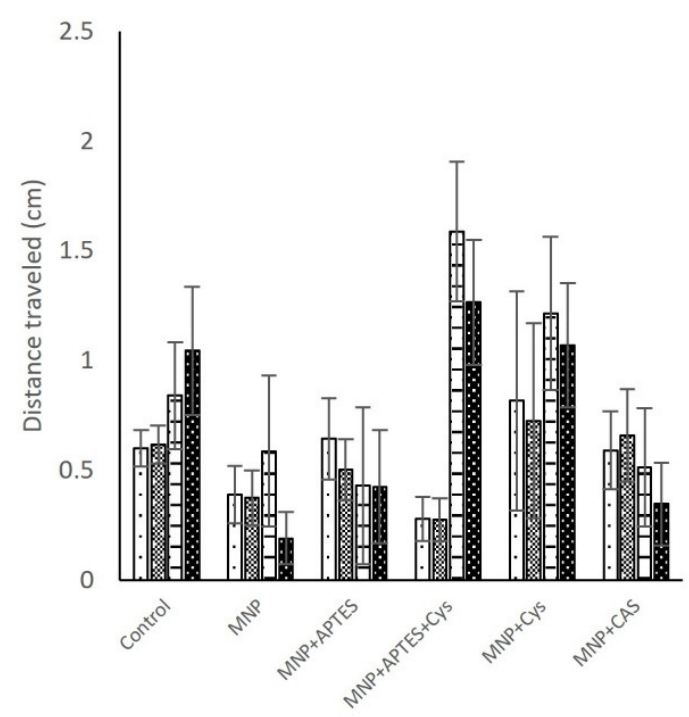

(b)

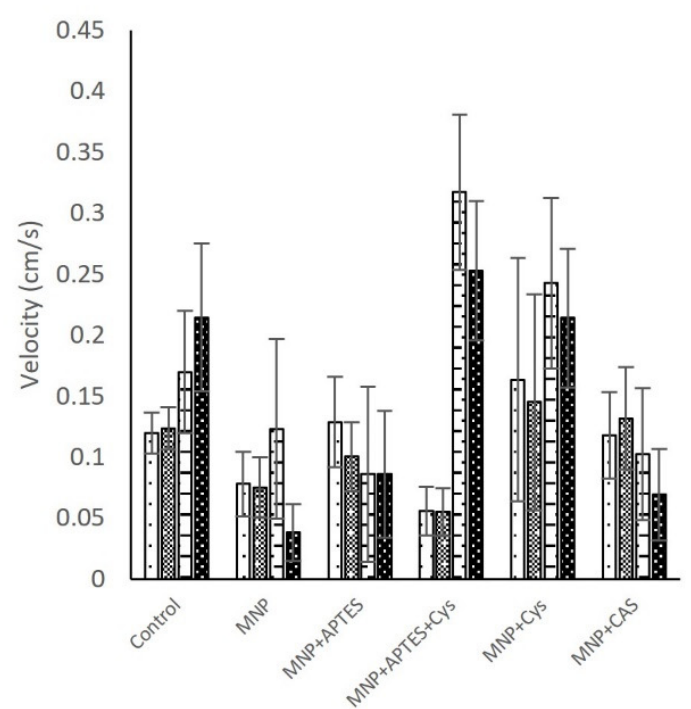

(c)
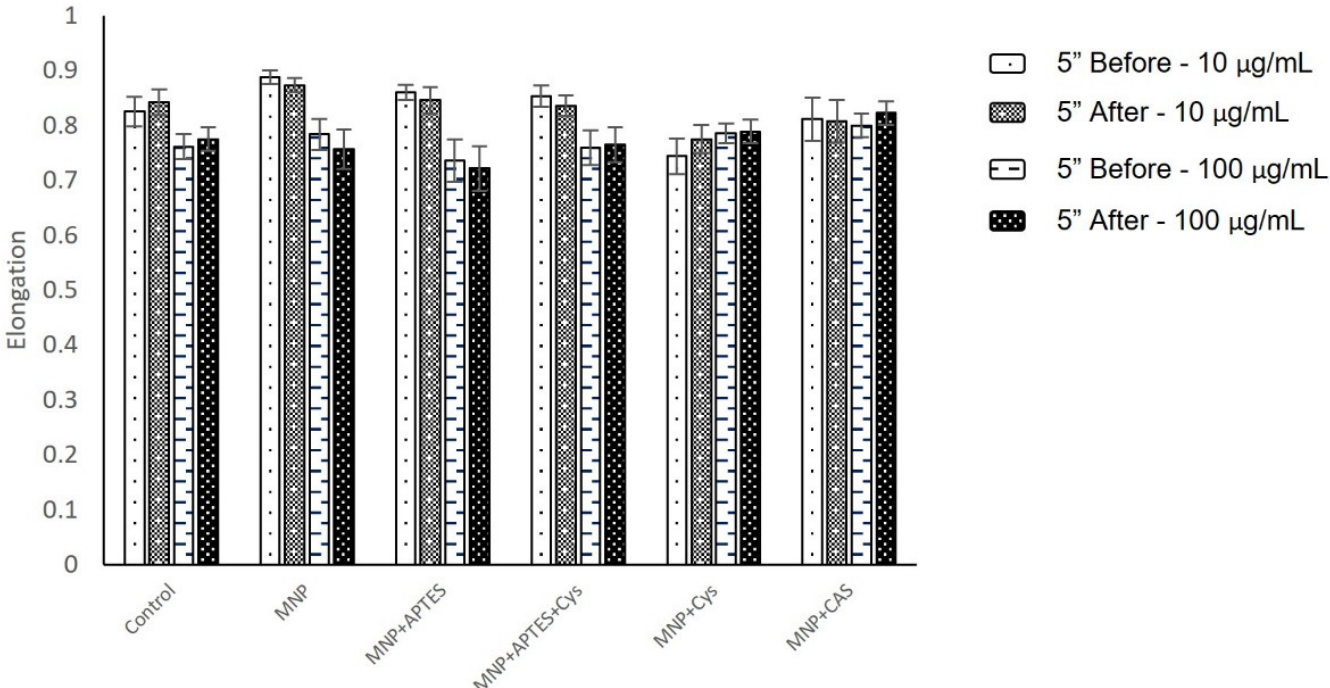

5" After $-100 \mu \mathrm{g} / \mathrm{mL}$

Figure 7. Startle response analysis in larvae that were subjected to nanocomposite treatments at 10 and $100 \mu \mathrm{g} / \mathrm{mL}$, between 6 to $10 \mathrm{dpf}$ : (a) distance traveled; (b) average speed; (c) elongation. Data are expressed as the mean $\pm \operatorname{SEM}(n=15)$.

Table 3. Distance traveled $(\mathrm{cm})$ during the startle response test in larvae that were subjected to nanocomposite treatments at 10 and $100 \mu \mathrm{g} / \mathrm{mL}$ between 6 to $10 \mathrm{dpf}$.

\begin{tabular}{|c|c|c|c|c|c|c|c|c|}
\hline \multirow{3}{*}{ Nanocomposite } & \multicolumn{8}{|c|}{ Distance Traveled (cm) } \\
\hline & \multicolumn{4}{|c|}{$5^{\prime \prime}$ Before } & \multicolumn{4}{|c|}{$5^{\prime \prime}$ After } \\
\hline & $100 \mu \mathrm{g} / \mathrm{mL}$ & SEM & $10 \mu \mathrm{g} / \mathrm{mL}$ & SEM & $100 \mu \mathrm{g} / \mathrm{mL}$ & SEM & $10 \mu \mathrm{g} / \mathrm{mL}$ & SEM \\
\hline MNP & 0.59 & 0.34 & 0.39 & 0.13 & 0.19 & 0.11 & 0.37 & 0.12 \\
\hline MNP+APTES & 0.43 & 0.36 & 0.64 & 0.18 & 0.42 & 0.25 & 0.50 & 0.14 \\
\hline MNP+APTES+Cys & 1.59 & 0.32 & 0.28 & 0.10 & 1.26 & 0.28 & 0.27 & 0.09 \\
\hline MNP+Cys & 1.21 & 0.35 & 0.82 & 0.49 & 1.07 & 0.28 & 0.73 & 0.44 \\
\hline $\mathrm{MNP}+\mathrm{CAS}$ & 0.51 & 0.27 & 0.59 & 0.18 & 0.35 & 0.18 & 0.66 & 0.21 \\
\hline Control & 0.84 & 0.24 & 0.60 & 0.08 & 1.04 & 0.29 & 0.62 & 0.09 \\
\hline
\end{tabular}


Table 4. Velocity $(\mathrm{cm} / \mathrm{s})$ during the startle response test in larvae that were subjected to nanocomposite treatments at 10 and $100 \mu \mathrm{g} / \mathrm{mL}$ between 6 to $10 \mathrm{dpf}$.

\begin{tabular}{|c|c|c|c|c|c|c|c|c|}
\hline \multirow{3}{*}{ Nanocomposite } & \multicolumn{8}{|c|}{ Velocity (cm/s) } \\
\hline & \multicolumn{4}{|c|}{$5^{\prime \prime}$ Before } & \multicolumn{4}{|c|}{$5^{\prime \prime}$ After } \\
\hline & $100 \mu \mathrm{g} / \mathrm{mL}$ & SEM & $10 \mu \mathrm{g} / \mathrm{mL}$ & SEM & $100 \mu \mathrm{g} / \mathrm{mL}$ & SEM & $10 \mu \mathrm{g} / \mathrm{mL}$ & SEM \\
\hline MNP & 0.12 & 0.07 & 0.08 & 0.02 & 0.04 & 0.02 & 0.08 & 0.02 \\
\hline MNP+APTES & 0.09 & 0.07 & 0.13 & 0.03 & 0.09 & 0.05 & 0.10 & 0.02 \\
\hline $\mathrm{MNP}+\mathrm{APTES}+\mathrm{Cys}$ & 0.32 & 0.06 & 0.06 & 0.02 & 0.25 & 0.05 & 0.06 & 0.02 \\
\hline $\mathrm{MNP}+\mathrm{Cys}$ & 0.24 & 0.06 & 0.16 & 0.09 & 0.21 & 0.05 & 0.15 & 0.08 \\
\hline $\mathrm{MNP}+\mathrm{CAS}$ & 0.10 & 0.05 & 0.12 & 0.03 & 0.07 & 0.03 & 0.13 & 0.04 \\
\hline Control & 0.17 & 0.05 & 0.12 & 0.02 & 0.21 & 0.06 & 0.12 & 0.02 \\
\hline
\end{tabular}

The color preference test evaluated the behavior of the larvae in terms of time and frequency in each monitored region (green and transparent). Overall, it appears that there were no significant differences between the animals in the nanocomposite treatment groups and the controls. At the concentration of $10 \mu \mathrm{g} / \mathrm{mL}$, there were statistically significant differences only for the larvae treated with MNP+CAS $(p=0.026)$. For the concentration of $100 \mu \mathrm{g} / \mathrm{mL}$, larvae treated with MNP were $8.6 \%$ above the control group in the green zone, as shown in Figure 8b; however, this was not statistically significant $(p=0.478)$. When the frequency of visits to the different zones was analyzed, animals treated with nanocomposites showed a lower frequency in the number of visits to the green zone compared to the control groups. This shows that there was less movement between zones in the nanocomposite-treated animals.

(a)

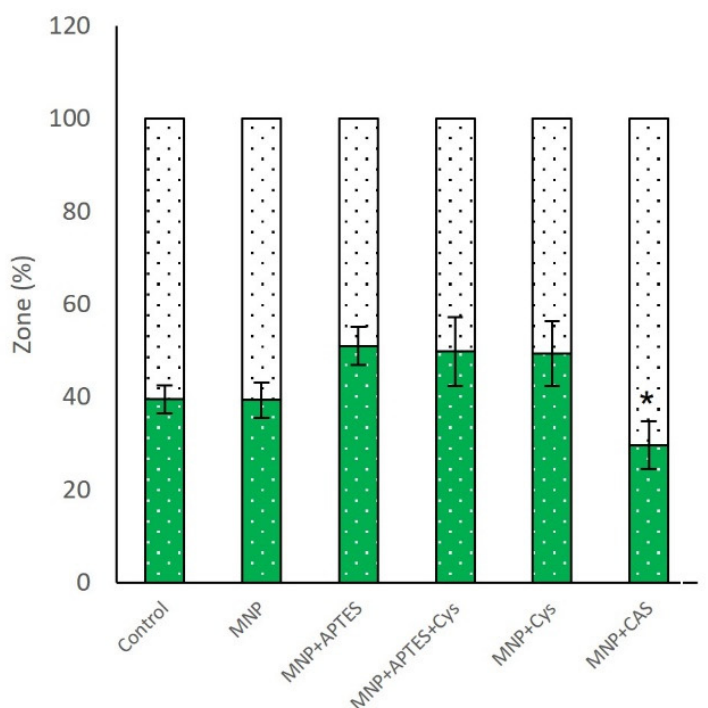

(b)

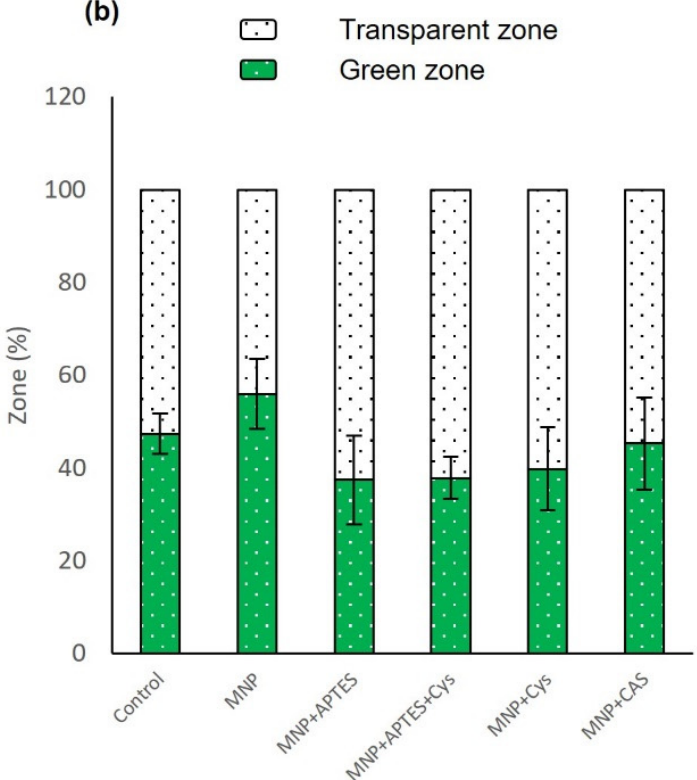

Figure 8. Color preference analysis in larvae that were subjected to nanocomposite treatments between 6 to $10 \mathrm{dpf}$. (a) Animals treated with nanocomposites at concentration of $10 \mu \mathrm{g} / \mathrm{mL}$ and control group. (b) Animals treated with nanocomposites at concentration of $100 \mu \mathrm{g} / \mathrm{mL}$ and control group. Data are expressed as the mean $\pm \operatorname{SEM}(n=15)$. The * represents significant difference $p \leq 0.05$ in relation to control group.

\subsection{Reproduction in Animals Treated with Nanocomposites}

Embryos and larvae subjected to nanocomposite treatment at $1000 \mu \mathrm{g} / \mathrm{mL}$ and raised for reproduction after month six showed an average fertility rate of $40.3 \%$, defined as the number of viable embryos $(\mathrm{Nv})$ at $24 \mathrm{hpf}$ over the total number of eggs collected $(\mathrm{Nt})$, calculated using the formula $\left(\mathrm{Nv}^{*} 100 \%\right) / \mathrm{Nt}$ [34]. The control group raised under 
the same conditions had an average fertility rate of $33 \%$. At one year, the fertility rates were reduced by an average of $23.7 \%$, while the number of eggs increased by about $57 \%$. Hatching rates of the total eggs collected from the 6-month age group averaged $52.4 \%$ in the nanocomposites-treated animals and $31.8 \%$ in the control animals, while in the 1-year age group hatching rates were $22.2,12.7$, and $24.8 \%$ for the nanocomposites-treated animals, control group (animals that were raised as controls for the experiment under the same conditions as the nanocomposite-treated animals), and internal control group (animals that were raised in an automatic recirculation system), respectively. Surviving larvae were observed until $13 \mathrm{dpf}$ and showed survival values between 85.4 and $94.8 \%$ for the 6-month age group in embryos treated with nanocomposites. They were outperformed by the control group by 1.7\%, as shown in Figure 9a. For the 1-year age group the survival was between 58.3 and $97.1 \%$, while the control group showed an average of $71.9 \%$ and the internal control group presented an average of $70.2 \%$, as shown in Figure $9 \mathrm{~b}$. When the groups were compared, there were no significant statistical differences showing that survival was treatment-dependent.
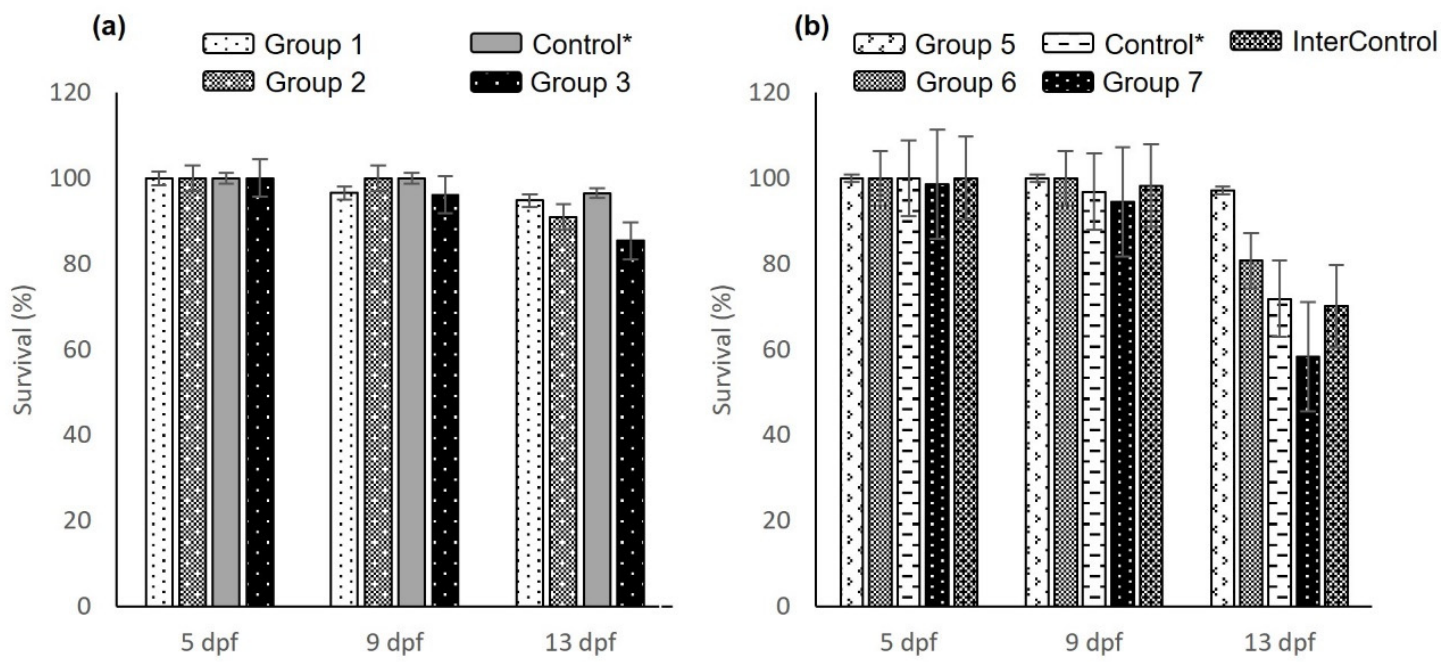

Figure 9. Survival analysis in animals that were subjected to nanocomposite treatments $(1000 \mu \mathrm{g} / \mathrm{mL})$ at embryonic and larval ages. (a) Survival of offspring in treated animals evaluated at embryonic and larval ages of 6 months post-treatment. Group 1: females (MNP+APTES+Cys) and males (MNP+Cys); Group 2: females (MNP+APTES+Cys) and males (MNP+CAS); Group 3: females $(\mathrm{MNP}+\mathrm{Cys})$ and males $(\mathrm{MNP}+\mathrm{CAS})$; Control $^{*}$ : animals that were raised as controls for the experiment under the same conditions as the nanocomposite-treated animals. (b) Survival of offspring in treated animals evaluated at embryonic and larval ages of one year post-treatment. Group 5: females $(\mathrm{MNP}+\mathrm{APTES}+\mathrm{Cys})$ and males (TABS AB); Group 6: females (MNP+Cys) and males (TABS AB); Group 7: females (MNP+APTES+Cys) and males (TABS AB); InterControl: internal control (TABS $\mathrm{AB} / \mathrm{TABS} \mathrm{AB})$. Data are expressed as the mean $\pm \mathrm{SEM}$.

\section{Discussion}

Nanocomposites dissolved in water are currently being evaluated for their effectiveness in the remediation of contaminated water [35-37]. Due to the development of this field of nanotechnology as a solution to current environmental problems, it is necessary to have efficient and effective assessment models to examine the impact of nanocomposites on living beings. In the present study, we analyzed the effects of exposure to magnetite-based nanocomposites on zebrafish embryos and larvae, as part of the investigation into the impact of the potential use of nanocomposites on biological systems. We evaluated the effect of nanocomposites on survival, morphology, and reproduction in the short and long term, as well as the behavioral changes of individuals such as locomotion activity, reaction to light stimulus, and color preference. The results of this study are subject to certain limitations. Some of the effects observed during and after exposure to magnetic 
nanocomposites may be due to alterations in physiological or molecular processes, or in the interactions of individuals, and this was not analyzed in the present study.

The results showed that the nanocomposites evaluated here were not toxic to zebrafish embryos and larvae. Animals treated with magnetite-based nanocomposites showed slight survival, morphology, and behavior variations. The slight changes noted here may be caused not by the magnetite core itself but rather by the functionalizations. One reason may be that the functionalizations cause the new nanocomposites to agglomerate and become unstable in biological or environmental media [38]. It has been found in previous studies that magnetite nanoparticles with and without surface functionalization can change their aggregation state in aqueous media, and this may depend on $\mathrm{pH}$ conditions as well as on exposure time [39] and concentration [40]. Although it has been shown that functionalization of magnetite nanoparticles can improve their stability and performance [41], their environmental toxicity still remains unknown. Studies have been undertaken that seek to measure the toxicity of magnetite-based nanoparticles with or without surface coatings. For example, starch-coated nanoparticles were found to be less toxic than bare nanoparticles when gene expression was evaluated in the gills and livers of adult zebrafish [42]. Our results suggest that the exposure time and lack of movement of the nanoparticles during the treatments may cause the observed agglomerations, and this should be further analyzed in future work.

Calculating the magnetite-based nanocomposite concentrations that may present an environmental or health risk might be difficult to achieve precisely. In this study, we have chosen concentrations for toxicity assessment in the range endorsed by the OECD (10 to $100 \mathrm{ug} / \mathrm{mL}$ ) [14], and in addition, we decided to test the much higher concentration of $1000 \mu \mathrm{g} / \mathrm{mL}$, in order to be more rigorous. Our results indicated that exposure of zebrafish embryos and larvae to most of the nanocomposites tested here did not affect the survival of the animals. Moreover, as we increased the concentration of the nanocomposites, the survival of the animals in both embryonic and larval stages decreased in different proportions, depending on the type of nanocomposite evaluated. When we tried to fit our data to equation models, we found that our data fitted a second-order polynomial equation model. For example, in embryos, the coefficient of determination $\mathrm{R}^{2}$ was 0.6923 for $\mathrm{MNP}+\mathrm{APTES}$ and 0.9654 for MNP+Cys, which were the extremes of the nanocomposites evaluated. This means that within these ranges of data, we can predict the survival of the treated animals. On the other hand, the most significant changes were observed in embryos and larvae exposed to nanocomposites at $1000 \mu \mathrm{g} / \mathrm{mL}$. It is worth noting that even at this highest concentration, most of the animals survived to adulthood and bred successfully.

Post-treatment reproduction is a determining factor in analyzing the toxic effect of nanoparticles. However, to the best of our knowledge, post-treatment reproduction tests have not yet been reported in animal models that have been treated with nanocomposites at early ages, for example in embryonic or larval fish. Here, we show that zebrafish treated at embryonic and larval ages with magnetite-based nanocomposites survived to adulthood and had good reproductive rates. In addition, the concentration at which these animals were treated was above the maximum toxicity concentration recommended by the OECD $(100 \mu \mathrm{g} / \mathrm{mL})$ [14], i.e., a concentration of $1000 \mu \mathrm{g} / \mathrm{mL}$.

To understand the concentrations evaluated here and their use in environmental remediation, we refer to studies that have used magnetite-based nanocomposites for the removal of pollutants in water. In a study on the removal of arsenic (III and V) [43], the authors reported magnetite nanocomposite concentrations for the removal of this contaminant in water of between 0.5 and $2.5 \mathrm{~g} / \mathrm{L}$ ( 500 to $2500 \mu \mathrm{g} / \mathrm{mL}$ ). However, they showed reusability of up to five cycles and recovery rates of $99 \%$ for the nanocomposites [43]. This indicates that even if the highest concentration $(2500 \mu \mathrm{g} / \mathrm{mL})$ was used and $99 \%$ of these nanocomposites were recovered, only approximately $25 \mu \mathrm{g} / \mathrm{mL}$ of nanocomposites would remain in the environment (water). Another study on the removal of $\mathrm{Pb}$ (II) using magnetite-based nanocomposites [44] evaluated the removal at concentrations of 50 to $400 \mathrm{mg} / \mathrm{L}$ (50 to $400 \mu \mathrm{g} / \mathrm{mL}$ ). The authors presented reuse of the nanocomposites up to the fifth cycle with 
recovery percentages close to $85 \%$, indicating that at the highest concentration $(400 \mu \mathrm{g} / \mathrm{mL})$, $60 \mu \mathrm{g} / \mathrm{mL}$ of nanocomposites would remain in the environment. These values are important to highlight since some of the concentrations tested in our study exceeded these values and resulted in no or very low toxicity. This indicates that even if the nanocomposites proposed in this study were used, their environmental impact would be low since they could be recovered from water by taking advantage of the magnetic properties of their core (magnetite) [1,2].

Zebrafish have been used in environmental toxicology to study the effects of nanocomposites including metals, natural metalloids, synthetic compounds, pesticides, pharmaceuticals, and industrial sub-products [45]. Here, we show that zebrafish represent a suitable model to study the elements or compounds that contaminate waterbodies, as well as those that are used to mitigate them. Zebrafish present relevant characteristics for toxicity assessment, such as rapid organ formation, high fecundity rates, and low maintenance costs, compared to other animal models [46]. Zebrafish have been used as a toxicity model at different stages of their development to study the effects associated with different nanomaterials, nanocomposites, or nanoparticles. For example, zebrafish embryos have been used to study the toxicity of silver nanoparticles associated with their shape. In that study, it was determined that the shape of the nanoparticles can affect toxicity in embryos, and the authors concluded that flat nanoparticles were more harmful than spherical ones [47]. Another study used embryos to evaluate hatching rates, survival, heartbeat, and body length of zebrafish subjected to hematite $\left(\alpha-\mathrm{Fe}_{2} \mathrm{O}_{3}\right)$ nanoparticle treatments. Their results showed that toxicity was slight and was concentration-dependent, i.e., the higher the concentration, the greater the toxicity [48]. The toxicity of iron oxide nanoparticles with different coatings (dextran, chitosan, polyethylene glycol, carboxy-silane, and silica) on zebrafish embryos and larvae has also been reported. The results suggest that toxicity, as measured by hatching rate, malformations, behavior, and survival, was not observed for most of the nanocomposites, except those treated with chitosan, where mortality rates were $100 \%$ for concentrations higher than $2 \mathrm{mM}$ (millimolar), thus suggesting further investigation of these types of coatings [49]. Therefore, the zebrafish model is a valid model for evaluating the toxicity of simple or complex nanocomposites such as those evaluated in this study (MNP, MNP+APTES, MNP+APTES+Cys, MNP+Cys, and MNP+CAS).

\section{Conclusions}

In our study, we evaluated the possible effects of magnetic nanocomposites used for the bioremediation of contaminated water on zebrafish embryos and larvae. The nanocomposites evaluated here were not toxic since the results did not show significantly alteration in the survival, morphology, behavior, fertility, or reproduction of the animals subjected to treatment.

Our study demonstrated that exposure to magnetite-based nanocomposites (MNP+CAS, $\mathrm{MNP}+\mathrm{APTES}$, and MNP+APTES+Cys) at high concentrations $(1000 \mu \mathrm{g} / \mathrm{mL})$ can induce morphological and physiological alterations in the embryonic and larval stages that could lead to harmful effects, resulting in the reduced long-term survival of the animals (between 2 and $6 \pm 1 \%$ ). However, this concentration of nanocomposites never remains in the environment, since environmental remediation involves the recovery of the nanocomposites and subsequent reuse in different cycles, which has already been demonstrated by other studies that have used magnetite-based nanocomposites for the removal of pollutants in water $[43,44]$. 
Supplementary Materials: The following supporting information can be downloaded at: https: / / www.mdpi.com/article/10.3390/nano12030489/s1. Figure S1: Representation of experimental timeline. Notes: hpf: hours postfertilization, dpf: days postfertilization and mpf: months postfertilization. * After behavioral testing, these larvae were euthanized.

Author Contributions: Conceptualization, A.G., Y.A., V.A. and J.F.O.; methodology, A.G., Y.A., M.B., M.J.N., A.L.C., V.A. and J.F.O.; validation, A.G., Y.A., V.A. and J.F.O.; formal analysis, A.G., Y.A., V.A. and J.F.O.; investigation, A.G.; resources, V.A. and J.F.O.; data curation, A.G., Y.A. and V.A.; writing-original draft preparation, A.G., M.J.N., A.L.C. and M.B.; writing-review and editing, A.G., V.A. and J.F.O.; visualization, A.G.; supervision, V.A. and J.F.O.; project administration, A.G., V.A. and J.F.O. All authors have read and agreed to the published version of the manuscript.

Funding: This research was supported by Colciencias/Minciencias Grant 766-2016 “Formación de Capital Humano de Alto Nivel para el Departamento de Cesar" to A.G.

Institutional Review Board Statement: All protocols involving animals were approved by the Institutional Animal Care and Use Committee of Universidad de los Andes (CICUAL), C.FUA_19-004.

Informed Consent Statement: Not applicable.

Data Availability Statement: The data and contributions presented in the study are included in the article. Further inquiries can be directed to the corresponding author.

Acknowledgments: The authors would like to thank the Clean Room laboratory of the Department of Electrical and Electronic Engineering, the Neuroscience and Circadian Rhythms laboratory at the School of Medicine, and the Department of Biomedical Engineering for access to their facilities.

Conflicts of Interest: The authors declare no conflict of interest.

\section{References}

1. Aredes, S.; Klein, B.; Pawlik, M. The removal of arsenic from water using natural iron oxide minerals. J. Clean. Prod. 2013, 60, 71-76. [CrossRef]

2. Liu, S.; Zhao, Y.; Wang, T.; Liang, N.; Hou, X. Core-shell $\mathrm{Fe}_{3} \mathrm{O}_{4} @ \mathrm{MIL}-100(\mathrm{Fe})$ magnetic nanoparticle for effective removal of meloxicam and naproxen in aqueous solution. J. Chem. Eng. Data 2019, 64, 2997-3007. [CrossRef]

3. Peng, G.; Zhang, M.; Deng, S.; Shan, D.; He, Q.; Yu, G. Adsorption and catalytic oxidation of pharmaceuticals by nitrogen-doped reduced graphene oxide $/ \mathrm{Fe}_{3} \mathrm{O}_{4}$ nanocomposite. Chem. Eng. J. 2018, 341, 361-370. [CrossRef]

4. Kumari, P.; Shekhar; Parashara, H. $\beta$-cyclodextrin modified magnetite nanoparticles for efficient removal of eosin and phloxine dyes from aqueous solution. Mater. Today Proc. 2018, 5, 15473-15480. [CrossRef]

5. Jv, X.; Zhao, X.; Ge, H.; Sun, J.; Li, H.; Wang, Q.; Lu, H. Fabrication of a magnetic poly(aspartic acid)-Poly(acrylic acid) hydrogel: Application for the adsorptive removal of organic dyes from aqueous solution. J. Chem. Eng. Data 2019, 64, 1228-1236. [CrossRef]

6. Zhang, J.; Lu, T.; Wang, Z.; Wang, Y.; Zhong, H.; Shen, P.; Wei, Y. Effects of magnetite on anaerobic digestion of swine manure: Attention to methane production and fate of antibiotic resistance genes. Bioresour. Technol. 2019, 291, 121847. [CrossRef]

7. Farrell, J.W.; Fortner, J.; Work, S.; Avendano, C.; Gonzalez-Pech, N.I.; Zárate Araiza, R.; Li, Q.; Álvarez, P.J.J.; Colvin, V.; Kan, A.; et al. Arsenic Removal by Nanoscale Magnetite in Guanajuato, Mexico. Environ. Eng. Sci. 2014, 31, 393-402. [CrossRef]

8. Husnain, S.M.; Um, W.; Woojin-Lee; Chang, Y.-S. Magnetite-based adsorbents for sequestration of radionuclides: A review. RSC Adv. 2018, 8, 2521-2540. [CrossRef]

9. Gutierrez, A.M.; Dziubla, T.D.; Hilt, J.Z. Recent advances on iron oxide magnetic nanoparticles as sorbents of organic pollutants in water and wastewater treatment. Rev. Environ. Health 2017, 32, 111-117. [CrossRef]

10. Shahid, M.K.; Phearom, S.; Choi, Y.-G. Synthesis of magnetite from raw mill scale and its application for arsenate adsorption from contaminated water. Chemosphere 2018, 203, 90-95. [CrossRef]

11. Abo Markeb, A.; Llimós-Turet, J.; Ferrer, I.; Blánquez, P.; Alonso, A.; Sánchez, A.; Moral-Vico, J.; Font, X. The use of magnetic iron oxide based nanoparticles to improve microalgae harvesting in real wastewater. Water Res. 2019, 159, 490-500. [CrossRef]

12. Molina, L.; Gaete, J.; Alfaro, I.; Ide, V.; Valenzuela, F.; Parada, J.; Basualto, C. Synthesis and characterization of magnetite nanoparticles functionalized with organophosphorus compounds and its application as an adsorbent for La (III), Nd (III) and $\operatorname{Pr}$ (III) ions from aqueous solutions. J. Mol. Liq. 2019, 275, 178-191. [CrossRef]

13. Halpern, B.; Frazier, M.; Potapenko, J.; Casey, K.; Koenig, K.; Longo, C.; Lowndes, J.; Rockwood, R.; Selig, E.; Selkoe, K.; et al Spatial and temporal changes in cumulative human impacts on the world's ocean. Nat. Commun. 2015, 6, 7615. [CrossRef]

14. Busquet, F.; Strecker, R.; Rawlings, J.M.; Belanger, S.E.; Braunbeck, T.; Carr, G.J.; Cenijn, P.; Fochtman, P.; Gourmelon, A.; Hübler, N.; et al. OECD validation study to assess intra- and inter-laboratory reproducibility of the zebrafish embryo toxicity test for acute aquatic toxicity testing. Regul. Toxicol. Pharmacol. 2014, 69, 496-511. [CrossRef]

15. Ruseell, W.M.S.; Burch, R.L. The Principles of Humane Experimental Technique; Universities Federation for Animal Welfare: Wheathampstead, UK, 1959; As reprinted 1992. 
16. Tannenbaum, J.; Bennett, B.T. Russell and Burch's 3Rs then and now: The need for clarity in definition and purpose. J. Am. Assoc. Lab. Anim. Sci. 2015, 54, 120-132.

17. MacArthur Clark, J. The 3Rs in research: A contemporary approach to replacement, reduction and refinement. Br. J. Nutr. 2018, 120, S1-S7. [CrossRef]

18. Lawrence, C.; Best, J.; James, A.; Maloney, K. The effects of feeding frequency on growth and reproduction in zebrafish (Danio rerio). Aquaculture 2012, 368-369, 103-108. [CrossRef]

19. Bootorabi, F.; Manouchehri, H.; Changizi, R.; Barker, H.; Palazzo, E.; Saltari, A.; Parikka, M.; Pincelli, C.; Aspatwar, A. Zebrafish as a Model Organism for the Development of Drugs for Skin Cancer. Int. J. Mol. Sci. 2017, 18, 1550. [CrossRef]

20. Howe, K.; Clark, M.D.; Torroja, C.F.; Torrance, J.; Berthelot, C.; Muffato, M.; Collins, J.E.; Humphray, S.; McLaren, K.; Matthews, L.; et al. The zebrafish reference genome sequence and its relationship to the human genome. Nature 2013, 496, 498-503. [CrossRef]

21. Baxendale, S.; van Eeden, F.; Wilkinson, R. The Power of Zebrafish in Personalised Medicine. Adv. Exp. Med. Biol. 2017, 1007, 179-197. [CrossRef]

22. Campaña, A.L.; Guillén, A.; Rivas, R.; Akle, V.; Cruz, J.C.; Osma, J.F. Functionalization and Evaluation of Inorganic Adsorbents for the Removal of Cadmium in Wastewater. Molecules 2021, 26, 4150. [CrossRef]

23. Sun, G.; Liu, K. Developmental toxicity and cardiac effects of butyl benzyl phthalate in zebrafish embryos. Aquat. Toxicol. 2017, 192, 165-170. [CrossRef]

24. Huang, H.; Huang, C.; Wang, L.; Ye, X.; Bai, C.; Simonich, M.; Tanguay, R.; Dong, Q. Toxicity, uptake kinetics and behavior assessment in zebrafish embryos following exposure to perfluorooctanesulphonicacid (PFOS). Aquat. Toxicol. 2010, 98, 139-147. [CrossRef]

25. Clavijo, C.; Osma, J.F. Functionalized Leather: A Novel and Effective Hazardous Solid Waste Adsorbent for the Removal of the Diazo Dye Congo Red from Aqueous Solution. Water 2019, 11, 1906. [CrossRef]

26. Perez, J.; Cifuentes, J.; Cuellar, M.; Suarez-Arnedo, A.; Cruz, J.C.; Muñoz-Camargo, C. Cell-penetrating and antibacterial BUF-II nanobioconjugates: Enhanced potency via immobilization on polyetheramine-modified magnetite nanoparticles. Int. J. Nanomed. 2019, 14, 8483-8497. [CrossRef]

27. Kuznowicz, M.; Jędrzak, A.; Leda, A.; Rębiś, T.; Jesionowski, T. Measurements of working parameters of external mediators for biodetectors based on the polydopamine@magnetite nanoparticles. Measurement 2021, 184, 109950. [CrossRef]

28. Jain, T.K.; Richey, J.; Strand, M.; Leslie-Pelecky, D.L.; Flask, C.A.; Labhasetwar, V. Magnetic nanoparticles with dual functional properties: Drug delivery and magnetic resonance imaging. Biomaterials 2008, 29, 4012-4021. [CrossRef]

29. Muthukumar, H.; Malla, S.; Matheswaran, M.; Gummadi, S.N. Immobilization of xylose reductase enzyme on cysteinefunctionalized Murraya koenigii mediated magnetite nanoparticles. Mater. Lett. 2020, 261, 127125. [CrossRef]

30. Bashir, A.; Pandith, A.H.; Malik, L.A.; Qureashi, A.; Ganaie, F.A.; Dar, G.N. Magnetically recyclable L-cysteine capped Fe ${ }_{3} \mathrm{O}_{4}$ nanoadsorbent: A promising $\mathrm{pH}$ guided removal of $\mathrm{Pb}(\mathrm{II}), \mathrm{Zn}(\mathrm{II})$ and $\mathrm{HCrO}_{4}{ }^{-}$contaminants. J. Environ. Chem. Eng. 2021, 9, 105880. [CrossRef]

31. Mbeh, D.A.; Mireles, L.K.; Stanicki, D.; Tabet, L.; Maghni, K.; Laurent, S.; Sacher, E.; Yahia, L.H. Human Alveolar Epithelial Cell Responses to Core-Shell Superparamagnetic Iron Oxide Nanoparticles (SPIONs). Langmuir 2015, 31, 3829-3893. [CrossRef]

32. Ognjanović, M.; Stanković, D.M.; Jaćimović, Ž.K.; Kosović-Perutović, M.; Dojčinović, B.; Antić, B. The effect of surface-modifier of magnetite nanoparticles on electrochemical detection of dopamine and heating efficiency in magnetic hyperthermia. J. Alloys Compd. 2021, 884, 161075. [CrossRef]

33. Zhang, B.; Wang, Y.; Zhang, J.; Qiao, S.; Fan, Z.; Wan, J.; Chen, K. Well-defined 3-Aminopropyltriethoxysilane functionalized magnetite nanoparticles and their adsorption performance for partially hydrolyzed polyacrylamide from aqueous solution. Colloids Surf. A Physicochem. Eng. Asp. 2020, 586, 124288. [CrossRef]

34. Chen, Y.; Wang, H.; Wang, F.; Chen, C.; Zhang, P.; Song, D.; Luo, T.; Xu, H.; Zeng, X. Sperm motility modulated by Trpv1 regulates zebrafish fertilization. Theriogenology 2020, 151, 41-51. [CrossRef]

35. Mohmood, I.; Lopes, C.B.; Lopes, I.; Ahmad, I.; Duarte, A.C.; Pereira, E. Nanoscale materials and their use in water contaminants removal-A review. Environ. Sci. Pollut. Res. 2013, 20, 1239-1260. [CrossRef]

36. Ezzatahmadi, N.; Ayoko, G.A.; Millar, G.J.; Speight, R.; Yan, C.; Li, J.; Li, S.; Zhu, J.; Xi, Y. Clay-supported nanoscale zero-valent iron composite materials for the remediation of contaminated aqueous solutions: A review. Chem. Eng. J. 2017, 312, 336-350. [CrossRef]

37. Jia, H.-R.; Zhu, Y.-X.; Duan, Q.-Y.; Chen, Z.; Wu, F.-G. Nanomaterials meet zebrafish: Toxicity evaluation and drug delivery applications. J. Control. Release 2019, 311-312, 301-318. [CrossRef]

38. Revia, R.A.; Zhang, M. Magnetite nanoparticles for cancer diagnosis, treatment, and treatment monitoring: Recent advances Mater. Today 2016, 19, 157-168. [CrossRef] [PubMed]

39. Hakami, O.; Zhang, Y.; Banks, C.J. Influence of aqueous environment on agglomeration and dissolution of thiol-functionalised mesoporous silica-coated magnetite nanoparticles. Environ. Sci. Pollut. Res. 2015, 22, 3257-3264. [CrossRef]

40. Jin, D.; Kim, S.H.; Kim, H. Concentration and Magnetic Field Effects on Thermal Fluctuation of Magnetic Weight of Magnetite Nanoparticles During Agglomeration Under Magnetic Field. Bull. Korean Chem. Soc. 2020, 41, 628-633. [CrossRef]

41. Pan, Z.; Li, W.; Fortner, J.D.; Giammar, D.E. Measurement and Surface Complexation Modeling of U(VI) Adsorption to Engineered Iron Oxide Nanoparticles. Environ. Sci. Technol. 2017, 51, 9219-9226. [CrossRef] 
42. Zheng, M.; Lu, J.; Zhao, D. Effects of starch-coating of magnetite nanoparticles on cellular uptake, toxicity and gene expression profiles in adult zebrafish. Sci. Total Environ. 2018, 622-623, 930-941. [CrossRef]

43. Ayub, A.; Raza, Z.A.; Majeed, M.I.; Tariq, M.R.; Irfan, A. Development of sustainable magnetic chitosan biosorbent beads for kinetic remediation of arsenic contaminated water. Int. J. Biol. Macromol. 2020, 163, 603-617. [CrossRef]

44. Fan, H.; Ma, X.; Zhou, S.; Huang, J.; Liu, Y.; Liu, Y. Highly efficient removal of heavy metal ions by carboxymethyl celluloseimmobilized $\mathrm{Fe}_{3} \mathrm{O}_{4}$ nanoparticles prepared via high-gravity technology. Carbohydr. Polym. 2019, 213, 39-49. [CrossRef]

45. Bambino, K.; Chu, J. Chapter Nine-Zebrafish in Toxicology and Environmental Health. Curr. Top. Dev. Biol. 2017, 124, 331-367.

46. Bai, C.; Tang, M. Toxicological study of metal and metal oxide nanoparticles in zebrafish. J. Appl. Toxicol. 2020, 40, 37-63. [CrossRef]

47. Abramenko, N.B.; Demidova, T.B.; Abkhalimov, E.V.; Ershov, B.G.; Krysanov, E.Y.; Kustov, L.M. Ecotoxicity of different-shaped silver nanoparticles: Case of zebrafish embryos. J. Hazard. Mater. 2018, 347, 89-94. [CrossRef]

48. Madhubala, V.; Kalaivani, T.; Kirubha, A.; Prakash, J.S.; Manigandan, V.; Dara, H.K. Study of structural and magnetic properties of hydro/solvothermally synthesized $\alpha-\mathrm{Fe}_{2} \mathrm{O}_{3}$ nanoparticles and its toxicity assessment in zebrafish embryos. Appl. Surf. Sci. 2019, 494, 391-400. [CrossRef]

49. Oliveira, E.M.N.; Selli, G.I.; von Schmude, A.; Miguel, C.; Laurent, S.; Vianna, M.R.M.; Papaléo, R.M. Developmental toxicity of iron oxide nanoparticles with different coatings in zebrafish larvae. J. Nanopart. Res. 2020, 22, 87. [CrossRef] 